\title{
CARDIOTOCOGRAPH: ADMISSION TEST AND OUTCOME
}

\author{
Nesam Susana Minnalkodi ${ }^{1}$
}

${ }_{1}^{1}$ Professor and HOD, Department of Obstetrics \& Gynaecology, Government Chengalpattu Medical College.

\section{ABSTRACT}

The main objective of intrapartum fetal monitoring is reduction or prevention of congenital neurological deficit and other intrapartum adverse events by screening for intrapartum hypoxia/acidosis. With an aim of evaluating role of admission test in predicting the adverse fetal outcome in high risk pregnancies in Government Chengalpattu Medical College, a cross-sectional study was designed including 50 high risk patients and 50 low risk patients. All the patients were subjected to a standard clinical evaluation using a proforma and subsequently subjected to admission test for 20 mins and their readings were grouped into 1 . Reactive, 2 . Suspicious, 3. Ominous. Intervention is planned based on the tracings of the admission test. The data from the admission test were compiled and subjected to statistical analysis. At the end of statistical analysis, it is found that electronic fetal monitoring has high sensitivity and low specificity. Antepartum risk factors are a poor predictors of fetal outcome. A normal tracing carries a predictive value of over $95 \%$ for APGAR score of 7 or greater and an abnormal tracing carries a predictive value of about $50 \%$ for APGAR score less than 7. In high risk cases admission test is more sensitive and in low risk cases the admission test is more specific. The negative predictive value for both groups were $85.2 \%$ and $97.7 \%$.

\section{KEYWORDS}

Cardiotocography, Fetal Distress, Fetal Hypoxia, Fetal Asphyxia, Admission Test.

HOW TO CITE THIS ARTICLE: Nesam Susana Minnalkodi. “Cardiotocograph: Admission Test and Outcome.” Journal of Evolution of Medical and Dental Sciences 2015; Vol. 4, Issue 102, December 21; Page: 16747-16753, DOI: 10.14260/jemds/2015/2508

\section{INTRODUCTION}

The main objective of intrapartum fetal monitoring is the reduction or prevention of congenital neurological deficiency by screening for intrapartum hypoxia/acidosis.1,2,3 thereby enabling obstetricians to undertake appropriate intervention. Although a majority of congenital neurological handicaps are not related to intrapartum events, intrapartum monitoring is undertaken to avoid deaths or morbidity due to intrapartum hypoxia.4 Monitoring is mainly performed by either intermittent auscultation or by Cardiotocography (CTG).5,6 Cardiotocography provides a continuous record of the Fetal Heart Rate (FHR) pattern over a desired length of time, usually a two channel chart with FHR on the upper channel and the frequency, duration and amplitude of uterine activity on the lower channel constituting the cardiotocography. Thus cardiotocography is a screening test for intrapartum fetal hypoxia and acidosis.7,8 (Low et al. 1999, Berkus et al. 1999).

Electronic Fetal Monitoring (EFM) reduces the risk of intrapartum fetal death from fetal hypoxia and prevents about one prenatal death per 1000 births. $^{3}$ (Vintzileos et al. 1993, 1995). Impey L, Reynolds M, Gates S conducted a randomized controlled trial on admission cardiotocography to compare the effect on neonatal outcome of admission cardiotocography versus intermittent auscultation of fetal heart rate. They found that the admission CTG group had good neonatal outcome than intermittent auscultation group $(\mathrm{P}=0.002)$. They concluded that routine use of admission cardiotocography had a role in improving neonatal outcomes. ${ }^{3}$ EFM was introduced in the 1970 s and by the 1990s was used in the intrapartum management of $75 \%$ of women in the USA (NCHS 1993).

Financial or Other, Competing Interest: None.

Submission 08-11-2015, Peer Review 09-11-2015,

Acceptance 24-11-2015, Published 19-12-2015.

Corresponding Author:

Dr. Nesam Susana Minnalkodi,

No. 53, Vedhachalam Nagar,

Chengalpattu, Kanchipuram District-603001,

Tamilnadu.

E-mail: minniesusan@yahoo.com

DOI:10.14260/jemds/2015/2508
Admission test is a good screening test because it is a simple test, noninvasive, easily perfomed and interpreted, having high acceptability by pregnant mothers, can be repeated at any time and high validity.1,2,3 Assessment on admission helps us to look carefully for high risk factors, particularly undetected and new factors that have appeared. ${ }^{9}$

\section{AIM OF THE STUDY}

1. Evaluation of the admission test in high risk and low risk groups.

2. Evaluation of the role of admission test in intrapartum patients admitted in labour ward in predicting adverse outcome of fetus at risk.

\section{MATERIALS AND METHODS}

Type of Study

Cross-sectional study.

\section{Cases}

One hundred patients admitted in labour ward - 50 high risk and 50 low risk cases.

\section{Inclusion Criteria}

Patients admitted in labour in active stage of labour after 37 completed weeks of gestation.

\section{Exclusion Criteria}

- Cephalopelvic disproportion.

- Prolonged labour.

- Previous LSCS with recurrent indication.

- Cord prolapse.

- Abruptio placentae.

- Rupture uterus.

Materials Needed

- Ultrasound transducer.

- Transducer belt and buckle set.

- Tocodynamometer.

- Chart paper.

- USG coupling gel.

- Pinard's fetoscope. 


\section{Place}

Chengalpattu Medical College Hospital, Chengalpattu.

\section{METHOD OF STUDY}

Antenatal women who were admitted in the labour ward in labour were taken for the study based on the inclusion and exclusion criteria. After eliciting the history and complete clinical examination of the patient, consent was obtained from each patient for admission test. Before getting a consent from the patients, the entire procedure is explained to her. A standard clinical proforma has been formulated and being used for all cases. The admission test is perfomed on each patient for 20 minutes. The admission test tracings were typed into:

1. Reactive.

2. Suspicious.

3. Ominous.

Depending on the type of tracings, the mode of management varies. Patients with normal tracings were followed by intermittent auscultation and electronic monitoring once in 3 to $4 \mathrm{hrs}$. Emergency interventions were made when we suspected fetal distress. In patients with suspicious tracings, immediate ARM done and the color of liquor was assessed.10,11,12,13 Amnioinfusion was given in patients with thin meconium stained amniotic fluid. ${ }^{8}$ The patients were carefully followed by CTG monitoring.

When there is a change in the colour of liquor or when ominous pattern appears on CTG recordings according to the stage of labour, the labour was terminated by either forceps or caesarean section. The findings were correlated with the outcome of pregnancy. To evaluate the outcome of pregrancy, fetal distress was considered to be present when ominous FHR changes lead to caesarean section or forceps delivery and the newborn had an APGAR score of $<7$ at $5 \mathrm{~min}$ of delivery (Arulkumaran et al.).

\section{STATISTICS}

Data collected were subjected to statistical analysis. Continuous variables are presented as mean $\pm \mathrm{SD}$; ordinal and nominal data are presented as number and percentage. Comparison between the groups were made using student's ' $\mathrm{T}$ ' test for quantitative data and Chi square test for qualitative data. A value of $\mathrm{P}<0.05$ was considered significant. Data are analyzed using statistical software package SPSS 17.0.

\section{RESULTS AND ANALYSIS}

\begin{tabular}{|c|c|c|}
\hline AGE (YEARS) & NO. OF CASES & PERCENT \\
\hline $15-19$ & 10 & 10 \\
\hline $20-24$ & 50 & 50 \\
\hline $25-29$ & 34 & 34 \\
\hline $30-34$ & 4 & 4 \\
\hline $35-39$ & 2 & 2 \\
\hline TOTAL & $\mathbf{1 0 0}$ & $\mathbf{1 0 0}$ \\
\hline \multicolumn{2}{|c|}{ Table 1: Age Group Distribution } \\
\hline
\end{tabular}

A $50 \%$ of the patients fall in the 20-24 years group and $30 \%$ falls in the $25-29$ years group.

\begin{tabular}{|c|c|c|}
\hline GRAVIDA & NO. OF CASES & PERCENT \\
\hline PRIMI & 49 & 49 \\
\hline GRAVIDA 2 & 34 & 34 \\
\hline GRAVIDA 3 & 15 & 15 \\
\hline GRAVIDA 4 \& ABOVE & 2 & 2 \\
\hline TOTAL & $\mathbf{1 0 0}$ & $\mathbf{1 0 0}$ \\
\hline \multicolumn{2}{|c|}{ Table 2: Obstetric Index } \\
\hline
\end{tabular}

A $49 \%$ (49 cases) is constituted by primi; 33\% (33 cases) is constituted by second gravida.

\begin{tabular}{|c|c|c|}
\hline CASE & NO. OF CASES & PERCENT \\
\hline BOOKED & 93 & 93 \\
\hline UNBOOKED & 7 & 7 \\
\hline TOTAL & $\mathbf{1 0 0}$ & $\mathbf{1 0 0}$ \\
\hline \multicolumn{3}{|c|}{ Table 3: Type of Case } \\
\hline
\end{tabular}

\begin{tabular}{|c|c|c|}
\hline LABOUR & NO. OF CASES & PERCENT \\
\hline SPONTANEOUS & 80 & 80 \\
\hline INDUCED & 20 & 20 \\
\hline TOTAL & $\mathbf{1 0 0}$ & $\mathbf{1 0 0}$ \\
\hline \multicolumn{3}{|c|}{ Table 4: Type of Labour } \\
\hline
\end{tabular}

\begin{tabular}{|c|c|c|}
\hline RISK & $\begin{array}{c}\text { NO. OF } \\
\text { CASES }\end{array}$ & PERCENT \\
\hline ANEMIA & 5 & 5 \\
\hline $\begin{array}{c}\text { BAD OBSTETRIC } \\
\text { HISTORY }\end{array}$ & 3 & 3 \\
\hline GDM & 1 & 1 \\
\hline HEART DISEASE & 1 & 1 \\
\hline $\begin{array}{c}\text { PROLONGED PRIMARY } \\
\text { INFERTILITY }\end{array}$ & 1 & 1 \\
\hline IUGR & 4 & 4 \\
\hline $\begin{array}{c}\text { POST DATED } \\
\text { PREGNANCY }\end{array}$ & 22 & 22 \\
\hline PIH & 9 & 9 \\
\hline RH-VE & 4 & 4 \\
\hline LR & 50 & 50 \\
\hline TOTAL & $\mathbf{1 0 0}$ & $\mathbf{1 0 0}$ \\
\hline \multicolumn{2}{|c|}{ Table 5: Risk Factors } \\
\hline
\end{tabular}

Among 100 cases, $50 \%$ cases are high risk and $50 \%$ cases are low risk. In high risk category, $22 \%$ cases are postdated pregnancy.

\begin{tabular}{|c|c|c|}
\hline TEST & NO. OF CASES & PERCENT \\
\hline NORMAL & 71 & 71 \\
\hline SUSPICIOUS & 22 & 22 \\
\hline OMINOUS & 7 & 7 \\
\hline TOTAL & $\mathbf{1 0 0}$ & $\mathbf{1 0 0}$ \\
\hline \multicolumn{2}{|c|}{ Table 6: Admission Test Tracings } \\
\hline
\end{tabular}

Among 100 cases, normal tracings was observed in $71 \%$. Suspicious tracing in $22 \%$, ominous tracing was observed in $7 \%$ of patients.

\begin{tabular}{|c|c|c|}
\hline MODE & NO. OF CASES & PERCENT \\
\hline LABOUR NATURAL & 70 & 70 \\
\hline CAESAREAN SECTION & 16 & 16 \\
\hline FORCEOS DELIVERY & 14 & 14 \\
\hline TOTAL & $\mathbf{1 0 0}$ & $\mathbf{1 0 0}$ \\
\hline \multicolumn{2}{|c|}{ Table 7: Mode of Delivery } \\
\hline
\end{tabular}

\begin{tabular}{|c|c|c|c|c|}
\hline CTG & $\begin{array}{c}\text { LABOUR } \\
\text { NATURAL }\end{array}$ & $\begin{array}{c}\text { CAESAREAN } \\
\text { SECTION }\end{array}$ & $\begin{array}{c}\text { FORCEPS } \\
\text { DELIVERY }\end{array}$ & TOTAL \\
\hline NORMAL & 65 & 0 & 6 & 71 \\
\hline SUSPICIOUS & 5 & 9 & 8 & 22 \\
\hline OMINOUS & 0 & 7 & 0 & 7 \\
\hline TOTAL & $\mathbf{7 0}$ & $\mathbf{1 6}$ & $\mathbf{1 4}$ & $\mathbf{1 0 0}$ \\
\hline \multicolumn{4}{|l}{ Table 8: Mode of Delivery According to CTG Findings } \\
\hline
\end{tabular}

$\mathrm{P}=0.000$

There exists statistically significant relationship $(p<0.05)$ between non-reactive test and increased incidence of caesarean section and instrumental vaginal delivery.12,14,15

Among normal tracing, 65 cases delivered by labour natural and 6 delivered by forceps delivery. 
Among suspicious tracings, 9 cases delivered by caesarean section, 8 delivered by forceps delivery and all ominous cases were delivered by caesarean section.

\begin{tabular}{|c|c|c|c|c|}
\hline CTG & $\begin{array}{c}\text { LABOUR } \\
\text { NATURAL }\end{array}$ & $\begin{array}{c}\text { CAESAREAN } \\
\text { SECTION }\end{array}$ & $\begin{array}{c}\text { FORCEPS } \\
\text { DELIVERY }\end{array}$ & TOTAL \\
\hline NORMAL & 22 & 0 & 5 & 27 \\
\hline SUSPICIOUS & 5 & 7 & 6 & 18 \\
\hline OMINOUS & 0 & 5 & 0 & 5 \\
\hline TOTAL & $\mathbf{2 7}$ & $\mathbf{1 2}$ & $\mathbf{1 1}$ & $\mathbf{5 0}$ \\
\hline \multicolumn{7}{|l}{ Table 9: Mode of Delivery According to CTG in High Risk Cases } \\
\hline
\end{tabular}

$\mathrm{P}=0.000$

There exists statistically significant relationship $(p<0.05)$ between the results of admission test and mode of delivery among the total high risk cases.

Among normal tracing, 22 cases were delivered by labour natural and 5 delivered by forceps delivery. Among suspicious tracing 7 cases were delivered by caesarean section. 6 delivered by forceps delivery and all ominous cases were delivered by caesarean section.

\begin{tabular}{|c|c|c|c|c|}
\hline CTG & $\begin{array}{c}\text { LABOUR } \\
\text { NATURAL }\end{array}$ & $\begin{array}{c}\text { CAESAREAN } \\
\text { SECTION }\end{array}$ & $\begin{array}{c}\text { FORCEPS } \\
\text { DELIVERY }\end{array}$ & TOTAL \\
\hline NORMAL & 43 & 0 & 1 & 44 \\
\hline SUSPICIOUS & 0 & 2 & 2 & 4 \\
\hline OMINOUS & 0 & 2 & 0 & 2 \\
\hline TOTAL & $\mathbf{4 3}$ & $\mathbf{4}$ & $\mathbf{3}$ & $\mathbf{5 0}$ \\
\hline \multicolumn{5}{|c|}{ Table 10: Mode of Delivery According To CTG. } \\
In Low Risk Cases \\
\hline
\end{tabular}

$\mathrm{P}=0.000$

There exists statistically significant relationship $(\mathrm{P}<0.05)$ between the result of Admission Test and mode of delivery among the total low risk cases.16,17,18 Among normal tracing 43 cases were delivered by labour natural and 1 delivered by forceps delivery. Among suspicious tracings 2 cases were delivered by caesarean section. 2 delivered by forceps delivery and All ominous cases were delivered by caesarean section.

\begin{tabular}{|c|c|c|}
\hline APGAR & $\begin{array}{l}\text { NO. of } \\
\text { CASES }\end{array}$ & PERCENT \\
\hline NO ASPHYXIA (7-10) & 81 & 81 \\
\hline MODERATE ASPHYXIA(6-4) & 15 & 15 \\
\hline SEVERE ASPHYXIA $(<4)$ & 4 & 4 \\
\hline TOTAL & 100 & 100 \\
\hline
\end{tabular}

\begin{tabular}{|c|c|c|c|c|}
\hline CTG & $\begin{array}{c}\text { NO } \\
\text { ASPHYXIA } \\
(\mathbf{7 - 1 0})\end{array}$ & $\begin{array}{c}\text { MODERATE } \\
\text { ASPHYXIA } \\
(\mathbf{6 - 4})\end{array}$ & $\begin{array}{c}\text { SEVERE } \\
\text { ASPHYXIA } \\
(<\mathbf{4})\end{array}$ & TOTAL \\
\hline NORMAL & 66 & 5 & 0 & 71 \\
\hline SUSPICIOUS & 13 & 7 & 2 & 22 \\
\hline OMINOUS & 2 & 3 & 2 & 7 \\
\hline TOTAL & $\mathbf{8 1}$ & $\mathbf{1 5}$ & $\mathbf{4}$ & $\mathbf{1 0 0}$ \\
\hline \multicolumn{5}{|c}{} \\
\hline
\end{tabular}

$\mathrm{P}=0.000$

There exists statistically significant relationship $(\mathrm{p}<0.05)$ between the results of admission test and APGAR score among the total study cases. ${ }^{16,19}$

\begin{tabular}{|c|c|c|c|c|}
\hline CTG & $\begin{array}{c}\text { NO } \\
\text { ASPHYXIA(7-10) }\end{array}$ & $\begin{array}{c}\text { MODERATE } \\
\text { ASPHYXIA(6-4) }\end{array}$ & $\begin{array}{c}\text { SEVERE } \\
\text { ASPHYXIA(<4) }\end{array}$ & TOTAL \\
\hline NORMAL & 23 & 4 & 0 & 27 \\
\hline SUSPICIOUS & 12 & 5 & 1 & 18 \\
\hline OMINOUS & 1 & 2 & 2 & 5 \\
\hline TOTAL & $\mathbf{3 6}$ & $\mathbf{1 1}$ & $\mathbf{3}$ & $\mathbf{5 0}$ \\
\hline \multicolumn{4}{|l}{ Table 13: Apgar score According to CTG in High Risk Cases } \\
\hline
\end{tabular}

$\mathrm{P}=0.04$

There exists statistically significant relationship $(\mathrm{p}<0.05)$ between the results of admission test and APGAR score among the total high risk cases. $16,19,20$

\begin{tabular}{|c|c|c|c|c|}
\hline CTG & $\begin{array}{c}\text { NO } \\
\text { ASPHYXIA(7-10) }\end{array}$ & $\begin{array}{c}\text { MODERATE } \\
\text { ASPHYXIA(6-4) }\end{array}$ & $\begin{array}{c}\text { SEVERE } \\
\text { ASPHYXIA(<4) }\end{array}$ & TOTAL \\
\hline NORMAL & 43 & 1 & 0 & 44 \\
\hline SUSPICIOUS & 1 & 2 & 1 & 4 \\
\hline OMINOUS & 1 & 1 & 0 & 2 \\
\hline TOTAL & 45 & 4 & 1 & 50 \\
\hline \multicolumn{4}{|l}{ Table 14: Apgar Score According to CTG in Low Risk Cases } \\
\hline
\end{tabular}

There exists statistically significant relationship $(\mathrm{p}<0.05)$ between the results of APGAR score among low risk cases.

\begin{tabular}{|c|c|c|c|}
\hline FETAL DISTRESS & HIGH RISK & LOW RISK & TOTAL \\
\hline PRESENT & 14 & 5 & 19 \\
\hline ABSENT & 36 & 45 & 81 \\
\hline TOTAL & $\mathbf{5 0}$ & $\mathbf{5 0}$ & $\mathbf{1 0 0}$ \\
\hline \multicolumn{4}{|c}{ Table 15: Fetal Distress } \\
\hline
\end{tabular}

Fetal distress is present in 19 cases (14 in high risk and 5 cases in low risk). Since p=0.022 $(<0.05)$, there is a significant difference between fetal distress among high risk and low risk cases. 


\begin{tabular}{|c|c|c|c|}
\hline \multirow{2}{*}{ CTG } & \multicolumn{2}{|c|}{ FETAL DISTRESS } & \multirow{2}{*}{ TOTAL } \\
\cline { 2 - 4 } & YES & NO & \\
\hline NORMAL & 5 & 66 & 71 \\
\hline SUSPICIOUS & 9 & 13 & 22 \\
\hline OMINOUS & 5 & 2 & 7 \\
\hline TOTAL & $\mathbf{1 9}$ & $\mathbf{8 1}$ & $\mathbf{1 0 0}$ \\
\hline \multicolumn{3}{|c|}{ Table16: Results of Admission } \\
Test in Relation to Fetal Distress \\
\hline
\end{tabular}

$\mathrm{P}=0.000$

There exists statistically significant relationship $(<0.05)$ between the results of admission test and incidence of fetal distress among the total study cases. ${ }^{14,21,22}$

\begin{tabular}{|c|c|c|c|}
\hline \multirow{2}{*}{ CTG } & \multicolumn{2}{|c|}{ FETAL DISTRESS } & \multirow{2}{*}{ TOTAL } \\
\cline { 2 - 3 } & YES & NO & \\
\hline NORMAL & 4 & 23 & 27 \\
\hline SUSPICIOUS & 6 & 12 & 18 \\
\hline OMINOUS & 4 & 1 & 5 \\
\hline TOTAL & $\mathbf{1 4}$ & $\mathbf{3 6}$ & $\mathbf{5 0}$ \\
\hline \multicolumn{3}{|c|}{ Table 17: Results of Admission Test in Relation } \\
to Fetal Distress in High Risk Cases \\
\hline
\end{tabular}

$\mathrm{P}=0.010$

There exists statistically significant relationship $(p<0.05)$ between the results of admission test and incidence of fetal distress among the total high risk cases.

\begin{tabular}{|c|c|c|c|}
\hline \multirow{2}{*}{ CTG } & \multicolumn{2}{|c|}{ FETAL DISTRESS } & \multirow{2}{*}{ TOTAL } \\
\cline { 2 - 3 } & YES & NO & \\
\hline NORMAL & 1 & 43 & 44 \\
\hline SUSPICIOUS & 3 & 1 & 4 \\
\hline OMINOUS & 1 & 1 & 2 \\
\hline TOTAL & $\mathbf{5}$ & $\mathbf{4 5}$ & $\mathbf{5 0}$ \\
\hline \multicolumn{3}{|c|}{ Table 18: Results of Admission Test in Relation } \\
to Fetal Distress in Low Risk Cases \\
\hline
\end{tabular}

$\mathrm{P}=0.000$

There exists statistically significant relationship $(p<0.05)$ between the results of admission test and incidence of fetal distress among the total low risk cases.

\begin{tabular}{|c|c|c|c|}
\hline ADMISSION & HIGH RISK & LOW RISK & TOTAL \\
\hline YES & 14 & 5 & 19 \\
\hline NO & 36 & 45 & 81 \\
\hline TOTAL & $\mathbf{5 0}$ & $\mathbf{5 0}$ & $\mathbf{1 0 0}$ \\
\hline \multicolumn{4}{|c|}{ Table 19: NICU Admissions } \\
\hline
\end{tabular}

$\mathrm{P}=0.022$

Since $\mathrm{p}=0.022(<0.05)$. There is a significant difference between admission among high risk and low risk.

\begin{tabular}{|c|c|c|c|}
\hline \multirow{2}{*}{ TEST } & \multicolumn{2}{|c|}{ FETAL DISTRESS } & \multirow{2}{*}{ TOTAL } \\
\cline { 2 - 3 } & YES & NO & \\
\hline POSITIVE & 14 & 15 & 29 \\
\hline NEGATIVE & 5 & 66 & 71 \\
\hline TOTAL & $\mathbf{1 9}$ & $\mathbf{8 1}$ & $\mathbf{1 0 0}$ \\
\hline \multicolumn{3}{|c}{ Table 20: Prediction of Fetal Distress } \\
\hline
\end{tabular}

$\mathrm{P}=0.000$

Fetal distress prediction results are significantly related to screening test findings $(\mathrm{p}<0.05)$ among total cases.

Positive predictive value $=48.3$

Negative predictive value $=92.9$

Sensitivity $=73.6 \%$

Specificity $=81.4 \%$

\begin{tabular}{|c|c|c|c|}
\hline \multirow{2}{*}{ TEST } & \multicolumn{2}{|c|}{ FETAL DISTRESS } & \multirow{2}{*}{ TOTAL } \\
\cline { 2 - 3 } & YES & NO & \\
\hline POSITIVE & 10 & 13 & 23 \\
\hline NEGATIVE & 4 & 23 & 27 \\
\hline TOTAL & $\mathbf{1 4}$ & $\mathbf{3 6}$ & $\mathbf{5 0}$ \\
\hline \multicolumn{3}{|c|}{ Table 21: Prediction of Fetal Distress in High Risk } \\
\hline
\end{tabular}

$\mathrm{P}=0.000$

Fetal distress prediction results are significantly related to screening test findings $(\mathrm{p}<0.05)$ among total high risk cases. Positive Predictive value $=43.5$

Negative Predictive Value $=85.2$

Sensitivity $=71.4 \%$

Specificity $=63.9 \%$

\begin{tabular}{|c|c|c|c|}
\hline \multirow{2}{*}{ TEST } & \multicolumn{2}{|c|}{ FETAL DISTRESS } & \multirow{2}{*}{ TOTAL } \\
\hline & YES & NO & \\
\hline POSITIVE & 4 & 2 & 6 \\
\hline NEGATIVE & 1 & 43 & 44 \\
\hline TOTAL & 5 & 45 & 50 \\
\hline
\end{tabular}

$\mathrm{P}=0.031$

Fetal distress prediction results are significantly related to screening test findings $(\mathrm{p}<0.05)$ among total low risk cases. Positive Predictive value $=66.6$

Negative Predictive Value $=97.7$

Sensitivity $=80.0 \%$

Specificity $=95.5 \%$

\section{DISCUSSION}

The main objective of intrapartum fetal monitoring is the reduction or prevention of congenital neurological deficit by screening for intrapartum hypoxia or acidosis, thereby enabling obstetricians to take appropriate intervention. Although a majority of congenital neurological handicaps are not related to intrapartum events, intrapartum monitoring is undertaken to avoid deaths or morbidity due to intrapartum hypoxia. In this way, Electronic Fetal Monitoring (EFM) is a screening test for intrapartum fetal hypoxia/acidosis. (Low et al. 1999, Berkus et al. 1999).

\section{Age Group Distribution}

In this study, 100 antenatal women were included. Majority of the antenatal women (50\%) fall between 20 and 24 years. This is in accordance with more pregnancy in that particular age group; $34 \%$ is formed by $15-29$ years, $10 \%$ formed by $15-19$ years, $4 \%$ formed by $30-34$ years and $2 \%$ by $35-39$ years of age.

\section{Obstetric Index}

This study recorded $49 \%$ primi, $34 \%$ second gravida, $15 \%$ third gravida, $2 \%$ fourth gravida and above.

\section{Type of Case}

Regarding booking status of the patients, in this study, among 100 patients $93 \%$ were booked and the remaining $7 \%$ were unbooked. Booking has no significance in this study.

\section{Type of Labour}

The study registered $80 \%$ of labour by spontaneous onset and $20 \%$ of induced labour.

\section{Risk Factors}

The study recorded 50:50 low risk/high risk ratio. High risk factors were being postdated pregnancy $(22 \%)$, anaemia (5\%), Bad Obstetric History (3\%), GDM (1\%), Heart Disease $(1 \%)$, long period of primary infertility (1\%), IUGR (4\%), PIH (9\%), RH-ve (4\%). 
Majority being postdated pregnancy which constitutes about $22 \%$. Patients with no risk factors has been considered as low risk (50\%).

\section{Admission Test Tracings}

In this study out of 100 women, $71 \%$ of patients had reactive admission test tracings, $22 \%$ belonged to suspicious tracings, and $7 \%$ belonged to ominous group.

Of the 50 high risk cases normal tracings was observed in 27 cases, suspicious in 18 and ominous in 5 cases of the 50 low risk cases normal tracing was observed in 44 cases. Suspicious in 4 and ominous in 2 cases. In 2002 Kasthugei $\mathrm{P}$ Narogoni S, conducted a study on admission test - an effective risk screening tool with 500 patients. The tracings were: $86.6 \%(n-433)$ had reactive $7.4 \%(n-37)$ were belonged to suspicious group and $0.6 \%(\mathrm{n}-10)$ were belonged to ominous.

In Kandan Karibu Hospital, Singapore (1998), a study was conducted among 1000 antenatal women for admission test in high and low risk pregnancy. The tracings were reactive 982(4.3\%) suspicious $49(4.7 \%)$ and ominous $10(1 \%)$.

\section{Mode of Delivery According to Admission Test}

MacDonald et al. conducted a randomized trial on admission cardiotocography in 1000 antenatal women (1985.). Mode of delivery among them: SVD 31\%, IVD 9\%, CS 60\%. Most of the caesarean deliveries occurred in abnormal CTG group. They found a statistically significant relation between non-reactive tests and increased incidence of IVD and CS $(\mathrm{P}<005)$.

Ingemarsson et al. (1986) carried out a study in $1000 \mathrm{AN}$ women on efficacy of admission test in predicting neonatal outcome, their mode of delivery. SVD 45\%, IVD 6\% and CS $49 \%$. They also found that abnormal admission test tracings were associated with increased caesarean delivery than reactive tracings group $(\mathrm{p}<0.04)$.

Sandal J et al. and Gourounti did a study on effect of admission test on rate of CS, instrumental vaginal delivery and neonatal APGAR score. The relative risk for having a caesarean delivery (RR 1.2, CI 1.00-1.41) and instrumental delivery (RR $1 \%$, CI 1.00-1.18) were both high in abnormal tracings group. Similarly, the relative risk for low APGAR $(<7$ at $5 \mathrm{~min})$ was also high in abnormal tracings group (RR 1.35, CI 0.85-2.13) They concluded that abnormal (suspicious and ominous) admission test tracings were associated with increased risk of instrumental vaginal delivery and caesarean section and low 5 min APGAR score.

Manterola Awarez Angeles Weintraub did a study on admission test and fetal outcome (1989). They took 600 antenatal patients, observed that non-reactive tracings were significantly associated with increased risk of instrumental vaginal delivery, caesarean section and poor fetal outcome than reactive tracings group $(\mathrm{p}=0.03)$ on efficacy of admission test in predicting neonatal outcome, their mode of delivery. SVD 45\%, IVD 6\% and CS 49\%. They also found that abnormal admission test tracings were associated with increased caesarean delivery than reactive tracings group $(\mathrm{p}<0.04)$.

In a study conducted by Vinitha Das, GK Malik in 170 AN women on efficacy of admission test in predicting fetal jeopardy in labour, $60.97 \%$ of the abnormal tracings group had caesarean delivery. In reactive tracings group, only $45.7 \%$ of patients had caesarean delivery. They observed a significant relation between admission test tracings and mode of delivery $(\mathrm{p}=0.04)$.

In this study of the 100 cases, $70 \%$ delivered by labour natural, $16 \%$ delivered by LSCS and $14 \%$ by forceps delivery. On comparing admission test tracings the mode of delivery, among normal tracings 65 cases delivered by labour natural and 6 cases by forceps delivery. Among suspicious tracings, 5 cases delivered by labour natural, 9 cases were delivered by caesarean section, 8 cases delivered by forceps and all ominous (5) were delivered by caesarean section. There exists a significant relationship $(\mathrm{P}=0.000)$ between non-reactive tests and increased instrumental vaginal delivery and caesarean section.

Of the 50 high risk cases those with normal tracings, 22 cases delivered by labour natural, 5 delivered by forceps. In those with suspicious tracings (18), 5 delivered by labour natural, 7 by LSCS, 6 by forceps. All patients with ominous pattern (5) delivered by caesarean section.

Of the 50 low risk patients with normal tracings (44), 43 cases delivered by labour natural and one by forceps delivery. In those with suspicious tracings (4), 2 delivered by caesarean section and 2 by forceps. Caesarean section was done for ominous pattern (2).

\section{Apgar Score According To CTG}

Fayola A0, Sotiloye OS did a study on antenatal cardiotocography in 300 AN women in Nigeria. They analyzed that low APGAR $<7$ occurred most commonly in non-reactive tracings $(p=0.04)$. Reactive test was associated with 3 fold reduction in the incidence of low APGARs compared with nonreactive.

In 1984, a randomized controlled trial was conducted on admission test by Kidd LC, Smith R. In their study, they observed that frequency of intrapartum fetal distress and low APGAR score were similar in both reactive and abnormal tracings group.

In this study of 100 cases, 81 cases developed no asphyxia, 15 developed moderate asphyxia, 4 developed severe asphyxia. Of the 81 cases that developed no asphyxia, 66 cases showed normal tracing, 13 had suspicious tracing and 2 had ominous tracings. Of the 15 cases who developed moderate asphyxia 5 showed normal tracing, 7 showed suspicious tracing and 3 showed ominous tracing. Of the 4 cases who developed severe asphyxia, 2 showed suspicious tracings and 2 showed ominous tracings. There exists statistically significant relationship $(\mathrm{P}=0.000)$ between the results of admission test and the total study cases.

Of the 50 high risk cases 36 developed no asphyxia, 11 developed moderate asphyxia, 3 developed severe asphyxia. Of the 36 cases that developed no asphyxia, 23 showed normal tracing, 12 showed suspicious tracing, 1 showed ominous tracing. Of the 11 cases who developed suspicious tracing, 4 showed normal tracing, 5 showed suspicious tracing and 2 showed ominous tracing. Of the 3 cases who developed severe asphyxia, 1 showed suspicious tracing and 2 showed ominous tracing. There exists significant relationship $(\mathrm{P}=0.004)$ between the results of admission test and APGAR score among the high risk cases.

Of the 50 low risk cases 45 developed no asphyxia, 4 developed moderate asphyxia and one developed severe asphyxia. Of the 15 cases who developed no asphyxia, 43 cases showed normal tracing, one showed suspicious tracing and one showed ominous tracing. Of the 4 cases who showed moderate asphyxia, one showed normal tracing, 2 showed suspicious tracing and one showed ominous tracing. Of the one case who developed severe asphyxia, it showed suspicious tracing. There exists statistically significant relationship $(p=.003)$ between the results of admission test and APGAR score among the low risk cases.

\section{Results of Admission Test in Relation to Fetal Distress}

Pattison N, McCowan L did a study to assess the effects of cardiotocography on perinatal morbidity and mortality. They noted no significant effect of antenatal cardiotocography on perinatal outcome $(\mathrm{p}=0.14)$.

In the study conducted by Kidd LC, Smith R on antenatal cardiotocography in 396 antenatal patients (1985), there was 
no difference in fetal outcome of reactive and non-reactive group.

Fawole AO, Sotiloye OS did a study on antenatal cardiotocography (2007) in 150 women. They found that nonreactive test was strongly associated with poor fetal outcome $(p=0.04)$. They concluded that antenatal cardiotocography can be used in low resource settings for improving perinatal care.

ln this study of 100 cases, in those with normal tracings (71) 5 developed distress. In those with suspicious tracing (22) 9 developed distress. In those with ominous tracing (7) 5 developed distress. There exists statistically significant relationship ( $\mathrm{p}=.000)$ between the results of admission test and the incidence of fetal distress among the total study cases. In high risk cases in those with normal tracings (27) 4 developed fetal distress, in suspicious tracings (18) 6 developed distress, in ominous tracing (5) 4 developed distress. There exists statistically significant relationship $(p=.010)$ between the results of admission test and high risk cases.

In low risk cases in those with normal tracing (44) 1 developed distress, in suspicious tracing (4) 3 developed distress. In ominous tracing (2) 1 developed distress. There exists statistically significant relationship $(\mathrm{P}=0.000)$ between the results of admission test and low risk cases.

\section{NICU Admissions}

Atul K Sood did a study in 500 women on evaluation of admission test in low risk pregnancy. They found that $5 \mathrm{~min}$ APGAR score $<7$ and neonatal admissions were more commonly associated with nonreactive tracings than reactive tracings $(\mathrm{p}<0.005)$.

In 1989, Manterola Alvarez D, Angeles Weintraub conducted a study on admission test and perinatal outcome. They found a statistical significant correlation between suspicious and ominous tracings significant correlation between suspicious and ominous tracings and fetal condition at birth (APGAR <7) $\mathrm{p}=0.01$.

Pattison N, McCowan L did a study to assess the effects of antenatal cardiotocography on perinatal morbidity and mortality in 2000. No significant correlation existed between type of tracings and perinatal morbidity and mortality $(\mathrm{p}=0.18)$.

In this study, 19 cases were admitted in NICU due to fetal distress. Of the 50 high risk cases, 14 cases were admitted. Of the 50 low risk cases, 5 cases were admitted. There exists statistically significant relationship $(\mathrm{P}=0.022)$ between NICU admissions among high risk and low risk.

\section{Prediction of Fetal Distress}

Fetal prediction results are significantly related $(\mathrm{P}=0.000)$ to admission test findings among total cases. Sensitivity 73-6\%, specificity $81.4 \%$, positive predictive value -48.3 , negative predictive value 92.9 .

Fetal prediction results are significantly related $(\mathrm{P}=0.000)$ to admission test findings among high risk cases. Sensitivity $-71.4 \%$, specificity $-63.9 \%$, positive predictive value -43.5 , negative predictive value -85.2 .

Fetal prediction results are significantly related $(\mathrm{P}=0.031)$ to admission test findings among low risk cases. Sensitivity - $80 \%$, specificity - $95 \%$, positive predictive value 66.6, negative predictive value - 97.7.

In a study concluded by Atoll K. Sod in 2002 on admission test Sensitivity $41 \%$

Specificity $94 \%$

PPV 83

NPV 72

Ln 2001, Vinitha Das conducted a prospective randomized study on efficacy of admission test in predicting fetal distress.
She observed,

Sensitivity $38 \%$

Specificity $79 \%$

PPV 48

NPV 72

In a study conducted by Kushtagi P (2002) on labor admission test showed,

Sensitivity $53 \%$

Specificity $93 \%$

PPV 61

NPV 91

The value obtained in the present study compares favourably with the values of other studies indicating that reactive admission test correlates well with fetal well-being.

\section{SUMMARY}

This study was conducted among 100 term antenatal women, who were admitted in labour ward in active labour. Of those, about $50 \%$ fell in the age group of 20 to 24 years of age, 34\% in the range of 25 to 29 years, $10 \%$ between 15 and 19 years and about $6 \%$ were above 30 years of age.

of them primi constitutes $49 \%$, second gravida constitutes about $34 \%$, and third gravida $15 \%$ and $2 \%$ fourth gravida and above; $80 \%$ of them experienced spontaneous labour and 20\% experienced induced type of labour.

There was equal number of low risk and high risk cases. Among the high risk cases, 22 cases were postdated pregnancy, 9 cases were PIH, 4 cases were IUGR, 5 anaemia, 3 BOH, 1 GDM, 1 heart disease, 1 long period of primary infertility and 4 Rh-ve. Normal tracing was observed in 71 cases, suspicious tracings in 22 cases and ominous tracing in 7 cases.

Seventy cases delivered by labour natural, 16 cases delivered by caesarean section and 14 cases delivered by forceps; 81 cases developed no asphyxia, 15 cases developed moderate asphyxia and 4 cases developed severe asphyxia. Fetal distress was present in 19 cases (14 cases in high risk and 5 cases in low risk). Among normal tracing, 65 cases were delivered by labour natural and 6 delivered by forceps delivery. Among suspicious tracing 9 cases were delivered by caesarean section, 8 delivered by forceps delivery and all ominous cases are delivered by cesarean section.

Fetal distress prediction results are significantly related to screening test findings $(\mathrm{p}<0.05)$ among all the cases, both high risk and low risk. Diagnosis test shows $73.6 \%$ sensitivity in all cases; $71.4 \%$ sensitivity in high risk cases and $95.5 \%$ specificity in low risk cases.

\section{CONCLUSION}

In high risk cases, Admission Test (AT) is more sensitive, in low risk cases, AT is more specific. Overall, in both groups negative predictive value is $85.2 \%$ and $97.7 \%$.

AT is used to detect fetal well-being and fetal distress if present on admission. This helps us in identifying the group of women who will require continuous electronic monitoring or intermittent auscultation during the course of labour.

Antepartum risk factors are not accurate predictors of fetal outcome as fetal heart changes and acidosis occur in same frequency in high risk as well as low risk group during the course of labour.

Bearing the acute events during the course of labour, AT will be a good predictor of fetal well-being at the time of admission and during the next few hours of labour in term fetus.

It will not predict the development of fetal distress that develops several hours later.

EFM also reduces the risk of intrapartum fetal death from fetal hypoxia and prevents about one perinatal death per 1000 births. 
EFM has high sensitivity, but its specificity is low. A normal EFM pattern carries a predictive value of over $95 \%$ for APGAR score of 7 or greater, while an abnormal pattern carries predictive value of about $50 \%$ for APGAR score less than 7 .

Abnormal pattern seen in fetuses that subsequently develop untoward outcomes are also seen in fetuses with normal outcomes.

Despite the shortcomings of CTG and the controversies surrounding its clinical application in clinical practice it remains in widespread use because of lack of adequate alternatives.

Fetal hypoxia and acidosis may develop faster with an abnormal trace when there is scanty thick meconium, IUGR, intrauterine infection with pyrexia and/or pre or post term labour.

In the absence of fetal distress, alternative method of assessments such as fetal biophysical profile may be used.

\section{BIBLIOGRAPHY}

1. Misra R, Grundsell HG. Electronic fetal monitoring. A practical guide, New Delhi, BI publications 2004, p 53.

2. Freernan RK, Garite TH, Nageotte MP. Fetal monitoring 3rd ed. Philadelphia, Lippincott Williams and Wilkins 2003.

3. Impey L, Raymonds $\mathrm{M}$, MacQuilla $\mathrm{K}$, et al. Admission cardiotocography: A randomised controlled trial. Lancet 361:465, 2003 [PMID: 12583945]1238354].

4. American College of Obstetricians and Gynaecologists: Fetal heart patterns: monitoring, interpretation and management, technical bulletinno. 207 July 1995b.

5. Parer JT: electronic fetal heart rate monitoring: A story of survival. Obstet Gynecol Surv 58:561, 2003 [PMID:12972834].

6. American Academy of Pediatrics and the American College of Obstetricians and Gynecologists: Intrapartum and postpartum care of the mother. In Guidelines for Perinatal Care, 5th ed. Washington DC. AAP and ACOG 2002.

7. Berkus MD, Langer O, Samueloff A, et al. Electronic fetal monitoring; hats reassuring? Act obstet gynaecol Scand 78:15, 1999 [PMID:9926886].

8. Lowe TW, Leveno KJ, Quirk JG, et al. Sinusoidal fetal heart rate patterns after intrauterine transfusion. Obstet Gynecol 64:215, 1984.

9. Mires G, Williams F, Howie P: Randomized controlled trial of cardiotocography versus Doppler auscultation of fetal heart at admission in labour in low risk obstetric population. BMJ 322:1457, 2001 [PMID: 11408301].
10. Freeman RK: Problems with intrapartum fetal heart rate monitoring interpretation and patient management. Obstet Gynecol 100;813, 2002 [PMID].

11. Hornbuckle J, Vail A, Abrams KR, et al.; Bayesian interpretation of trials: The example of intrapartum electronic fetal heart rate monitoring, $\mathrm{Br} \mathrm{J}$ obstet gynaecol 107:3, 2000 [PMID:10645854].

12. American college of obstetricians and gynaecologists: Fetal heart patterns: monitoring, interpretation and management, technical bulletinno. 207 July 1995b.

13. American journal of obstetrics and gynaecology, vol 177, No. 6. National Institute of Child Health and Human Development Research Planning workshop, Electronic fetal heart rate monitoring: Research guidelines for interpretation, pp. 1385-1390.

14. Eagley CC. Prolonged end-stage fetal heart rate pattern during labour. Am J Perinatal 8:197.1991 [PMID:2029281].

15. Picquard F, Hsiung R, Mattauer M, et al. The validity of fetal heart rate monitoring during the second stage of labour. Obstet Gynaecol 72:746, 1988.

16. Krebs HB, Peters RE, Dunn LJ, et al.: Intrapartum fetal heart rate monitoring. 6 Prognostic significance of accelerations. Am J Obstet Gynaecol 142:297, 1982 [PMID: 7065019].

17. Hon EH, Bradfield AM, Hess OW: The electronic evaluation of the fetal heart rate. Am J Obstet Gynaecol 82:291, 1961 [PMID:13715643].

18. Hon EH: the electronic evaluation of the fetal heart rate. Am JObstet Gynaecol 75:1215, 1958 [PMID:13545252].

19. Elmina A, Figueroa R, Tejani N: Intrapartum assessment of fetal well-being: A comparison of scalp stimulation with scalp pH sampling. Obstet Gynecol 89:373, 1997 [PMID:9052588].

20. Thacker SB, Stroup DF, Peterson HB: Efficacy and safety of intrapartum electronic fetal monitoring: An update. Obstet Gynaecol 86:613, 1995 [PMID:7675390].

21. Boehm FH: Prolonged end-stage fetal heart rate deceleration. Obstet Gynaecol 45:142, 1975 [PMID:1124177].

22. Lee CV, DiLaretto PC, Lane JM: A study of fetal heart rate acceleration patterns. Obstet Gynaecol 45:142, 1975 [PMID:1118084]. 